\title{
Odontogenic Periorbital Cellulitis
}

Tahiriarivelo Randriamanantena ${ }^{1}$, Rantoniaina Rajaona ${ }^{2}$, Tina Ravololonirina ${ }^{3}$ and John Alberto Bam Razafindrabe $^{4}$

1. Department of Oral and Maxillofacial Surgery Unity, Hospital of Fianarantsoa, Fianarantsoa 301, Madagascar

2. Ophtalmology Unity, Hospital of Antananarivo University, Antananarivo 101, Madagascar

3. Department of Surgery, Hospital of Antananarivo, Antananarivo 101, Madagascar

4. Department of Oral and Maxillofacial Surgery Unity, Hospital of Antananarivo, Antananarivo 101, Madagascar

\begin{abstract}
Introduction: Periorbital cellulitis is an inflammation of the periorbital or preseptal soft tissue due to dental infection complication. It needs emergency surgery when collected to avoid septic spreading to noble organs. Patients and methods: This is a retrospective study enrolling 24 patients operated in Maxillofacial Surgery Unit at Joseph Dieudonné RAKOTOVAO University Hospital after diagnosis of preseptal or periobital cellulitis. Collected cellulitis were treated with drainage, antibiotherapy, analgesic and local application of antiseptic solution. Dental extraction was indicated in all patients. The purpose of the study is to evaluate the efficiency of these therapeutic schemes in the treatment of periorbital cellulitis and in the limitation of complications and after-effects. Results: Age range 21 to 30 years-old was mostly concerned. Fifty eight percent were men. Palpebral inflammation and chemosis were main clinical presentation. Instead of two cases of complications, 92\% patients had good outcomes. Conclusion: This study had demonstrated the efficiency of drainage plus antibiotherapy and dental extraction in the treatment of collected periorbital cellulitis.
\end{abstract}

Key words: Odontogenic orbital cellulitis, acute rhinosinusitis, orbital complication, computerized tomography, treatment.

\section{Introduction}

Periorbital or preseptal cellulitis is an inflammation of the periorbital soft tissue due to dental infection complication [1]. It is a rare infection but serious important complication and life-threatening pathology can be given the extension to the neighbooring structures mainly to the cerebral tissue. It can also impair the visual prognosis [2-5]. This study aims to evaluate the efficiency of our therapeutic schemes in the treatment of periorbital cellulitis with our local mean.

\section{Patients and Methods}

This is a descriptive and retrospective study carried out at Maxillofacial Surgery Unit of Joseph Dieudonné University Hospital of Antananarivo during a period of 24 months between January 2012

Corresponding author: Tahiriarivelo Randriamanantena, teacher and researcher in Medecine Universitiy of Fianarantsoa, research fields: oral and maxillofacial surgeon. and December 2013. Twenty four patients presented with isolated periorbital cellulitis after dental infection were enrolled on. The primary objective of the study was to evaluate our diagnostic tools and the efficiency of the treatment performed in our center.

Age, sex, risk factors of cellulitis, clinical signs, biological and radiological findings, causal dental infection, outcomes were studied. Dental panoramic $\mathrm{X}$-ray enabled the identification of the causal and Blondeau X-ray was required to explore maxillary sinus. All patients had received analgesic, antibiotics (Table 1) and anticoagulation treatment. Collected preseptal cellulitis $(46 \%)$ were treated with drainage plus antibiotherapy and the rest of our cases were not yet collected and treated only by medical mean.

The drainage was performed under local anaesthesia. Evacuation of pus was done after superior palpebral incision then purulent pockets are broken down by fingers or with clamps. The area was covered with physiological saline solution, antiseptic solution and hydrogen peroxyde. Then, the remaining cavity was 
Table 1 Antibiotics.

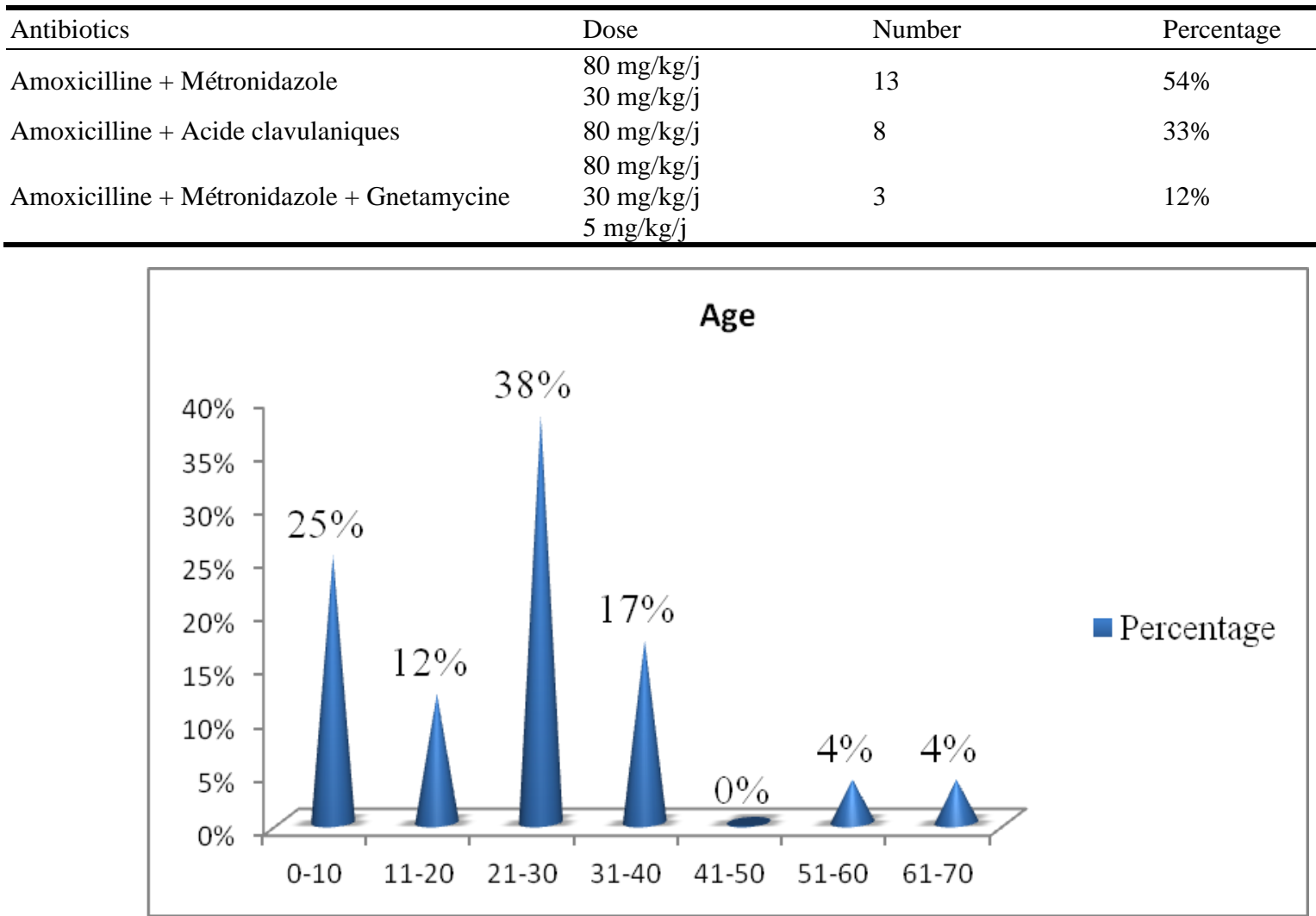

Fig. 1 Age of patients.

filled with gauze wick up and kept open for a few days. Gauze wick was changed every day until the cavity had completely drained and the wound healed. Patients were followed-up for a month postoperatively.

Dental extraction was indicated in all patients. For all collected cellulitis, this dental extraction was performed in the same time as drainage and for the others, extraction was done during the first week of the treatment session.

Disparition of clinical sign after two weeks of treatment was about $92 \%$ of all patients.

\section{Results}

Twenty four patient have been enrolled on during our study period. Mean age was 24 years old (3-61) peaking at range 21 to 30 (Fig. 1).

Fifty percent of our patients were men. The use of non-steroidal anti-inflammatory was the predominant risk factor (Fig. 2).

Maxillary premolars were mostly involved (Table 2).

Seventy percent of our patients had fever at examination. All patients had edema and palpebral inflammation. Twelve percent of patients had serious symptoms: Deterioration of their general condition, hyperthermia. Fourty six percent of patients had significant preseptal collection with complete closure of the eyeball. Panorex was indicated in all patient (Fig. 3).

Fourty one point six six percent $(41.66 \%)$ of our patients had sinusal pain. These patients complained about regular headache, cacosmia. Blondeau X-ray showed sinusal opacities in favour of associated sinusitis (Fig. 4).

Visual acuity and ocular motility were unimpaired in all patients. No patient benifited from CT scan nor antibiogram because of their lack of means. And $79.16 \%$ who had yet their teeth patients admitted dental 


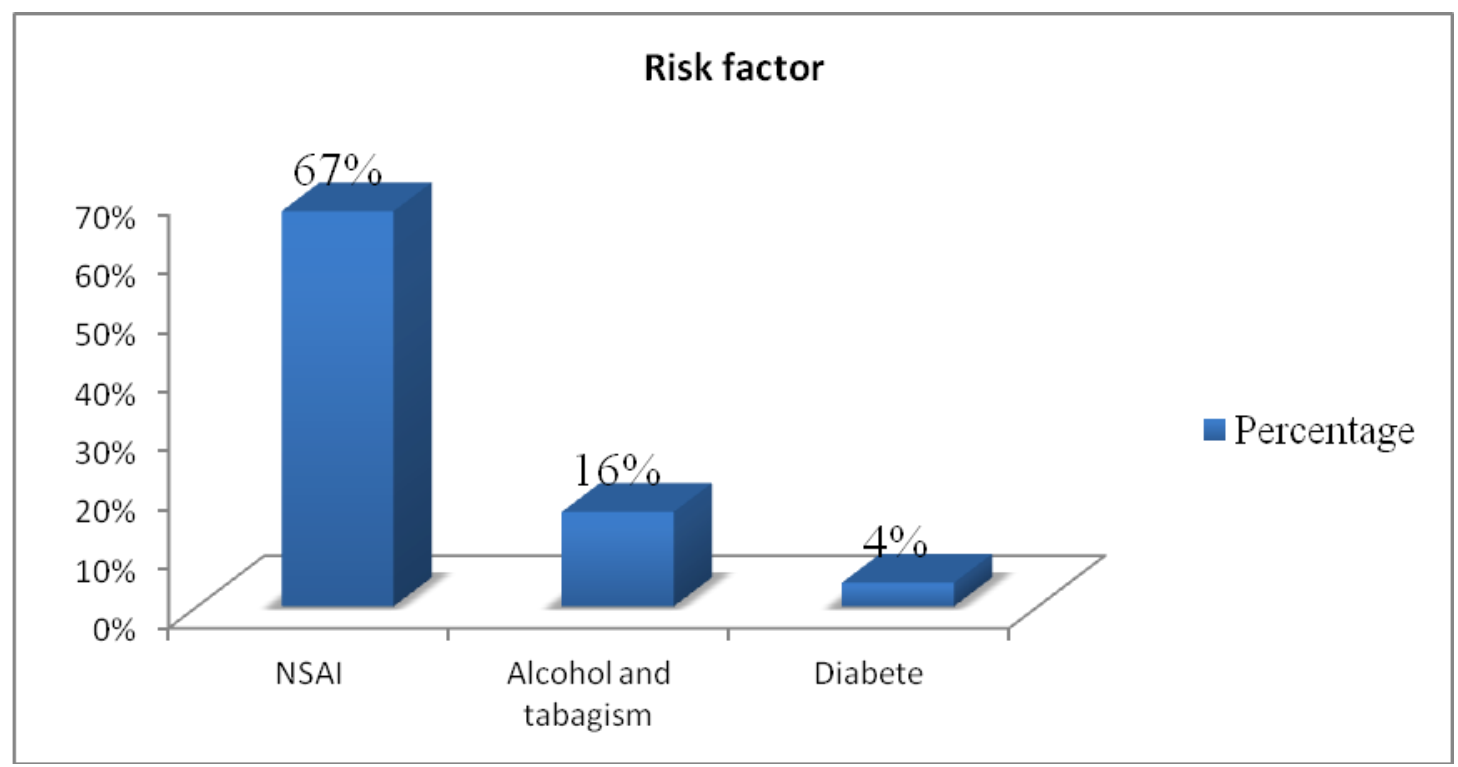

Fig. 2 Risk factor.

Table 2 Causal teeth proportion.

\begin{tabular}{ll}
\hline Teeth (maxillary teeth) & Percentage \\
\hline Premolars & $54 \%$ \\
First molars & $30 \%$ \\
Second molars & $4 \%$ \\
Third molars & $4 \%$ \\
Others teeth & $8 \%$ \\
\hline
\end{tabular}

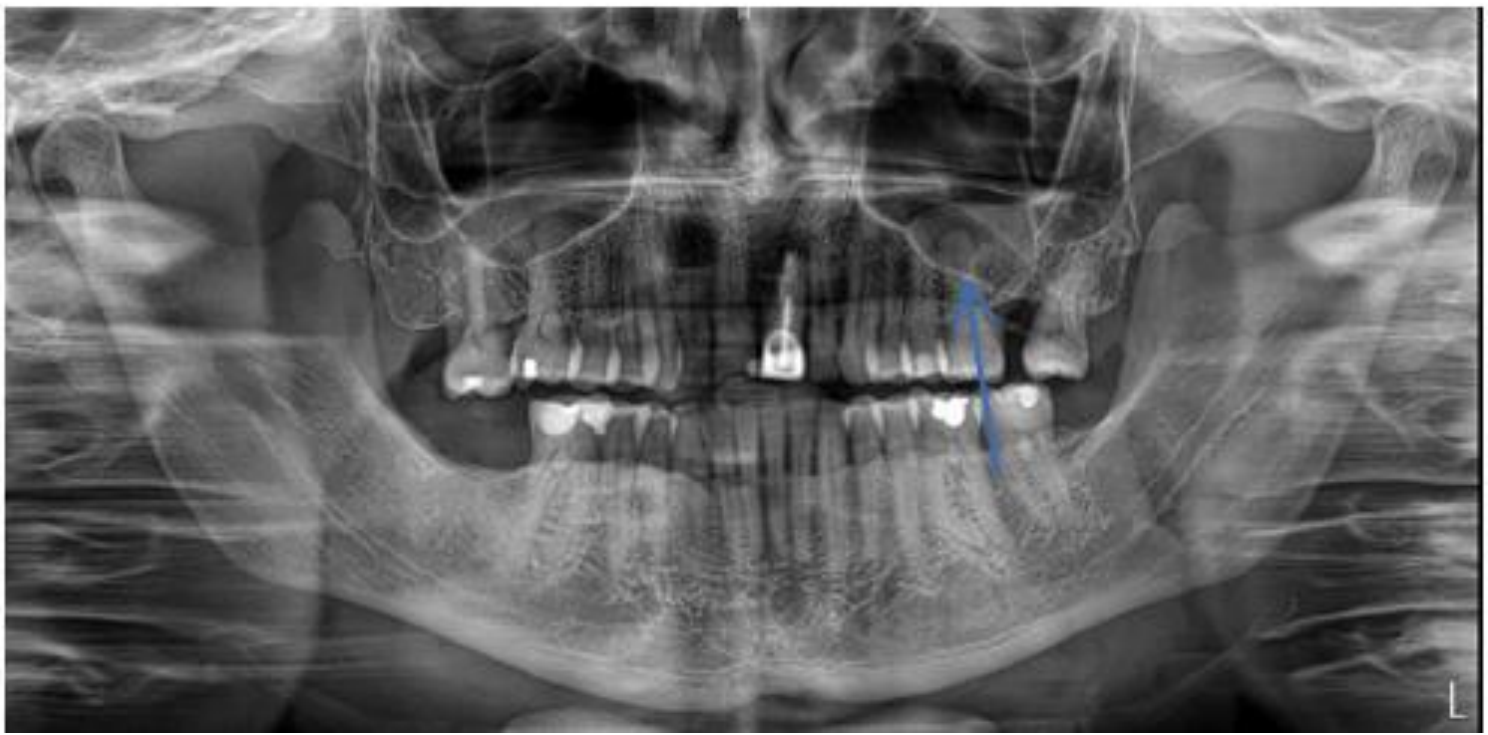

Fig. 3 Panorex of one causal tooth. 


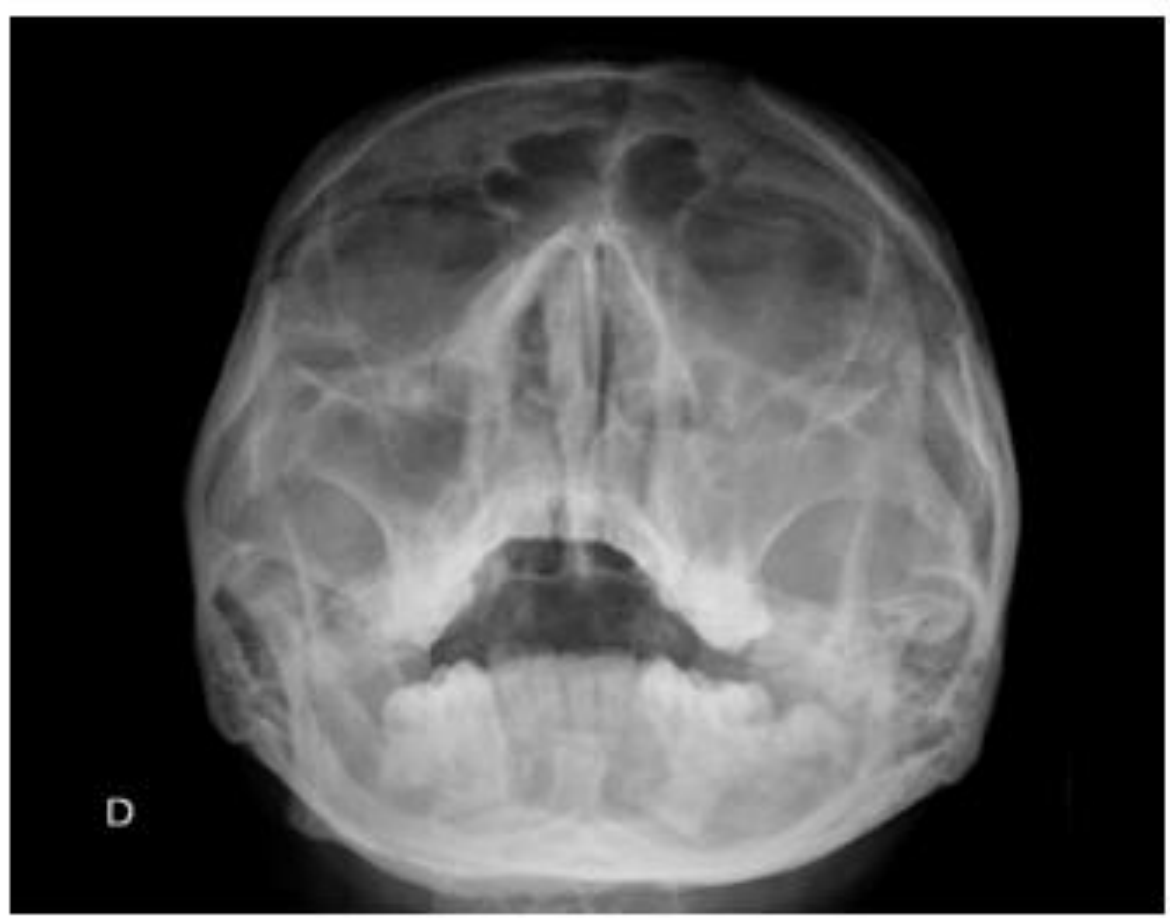

Fig. 4 X-RAY of maxillary sinus affect.

extraction. One patient died from septic schock in resuscitation unit and an another one had cerebral abcess which was an extension of the infection and was operated from cerebral abcess then recovered in 3 weeks. Despite those complications, $92 \%$ patients had good outcomes.

\section{Discussion}

Periobital cellulitis is an acute inflammation of the eyeball [3]. This pathology occurs in both developed and developing countries [4]. Donahue and Schwartz [4] reported only 10 cases in ten years in Tenessee. Uzcategui and Warman [5] reported a prevalence of $15.84 \%$ in a period of 4 years in Miami. Wane et al. [6] recorded an incidence of $7.5 \%$ to $8.89 \%$ per year in Senegal. These figures and ours witnessed the rarity of this pathology. In our center, this pathology is underestimated because some patients are referred to ophtalmolgy unit as it was also reported by Randrianjafisamindrakotroka [7]. Periorbital cellulitis is frequent in young patients but can also affect children when sinus is already developped. It can have a closed relation of sinusitis. Elderly patients are not excluded when they still have remaining teeth. The frequency in young people is priorly due to dental care negligence and pain endurance but it can also be explained by the fact that they have more teeth than children or elderly people. Nevertheless, some studies $[3,8]$ like ours show high frequency in children.

Few studies [3, 6, 9] reported male predominance as shown in our study. There are risk factors of complications from dental infection: Diabetes [9] that was found in one of our patients and the take of non-steroidal anti-inflammatory drugs (NSAIDs) [1, 9-11] that prevails in our study. NSAIDs are frequently taken in dental pain without any regard to the staging of the infection. If the infection has gone beyond acute pulpitis, taking NSAIDs which leads to immunity deficiency that promotes the germs expansion in spite of the inflammatory signs disappearance. In this way, NSAID alone or associated with underdosed antibiotics exacerbates infection [11, 12].

Periorbital cellulitis is frequently associated with sinusitis; $41 \%$ in our study. The infection affects the sinuses on the way but it can be caused by only 
sinusitis without dental origin [13-15]. Since 7 years old, it means maxillary sinuses have been developed, sinutis can be included in cellulitis having origin in oral cavity and passing by maxillary sinuses. But the pus dissemination can also goes through cellular and fatty tissues or through blood via jugular or ophtalmic vein $[13,16]$. The tooth root and his neighbooring muscular tissues can spread the infection [11].

Premolars and first molars are mostly concerned with periorbital cellulitis in our study and others [17]. Dental panoramic X-ray is the key-examination of the assessment of a dental aetiology and the causal teeth [11]. CT-scan is the reference investigation for the diagnosis of a collection. It allows staging of diagnosis depending Chandler classification, extension and surgical access. It sets the staging of cellulitis by Chandler [2, 3, 5, 18]. Despite of that, CT-scan was not performed in any patient because of lack of means. Ct-scan is very expensive. Indeed, meticulous clinical examination leaded to diagnosis in all cases. All signs of preseptal cellulitis have been enrolled and the lack of signs of the others stages allowed us to set preseptal cellulitis. Ocular signs like chemosis and palpebral edema are frequent but ocular motricity and visual acuity are preserved [2].

Blondeau skull X-ray assesses the maxillary sinus condition and the potential need of sinusal treatment $[3,19,20]$. Headache, unilateral nasal obstruction and cacosmy have lead us to ask X-ray which have shown homolateral opacity. In those cases, treatment is based on association of antibiotics, analgesic, antiseptic solution, which is mentionned in litterature; drainage and NSAIDs for its anti-oedematous effect [11, 21]. Antibiotic should be used according to the antimicrobial susceptibility but none of our patients benefited from antibiogram because of lack of means.

Dental extraction is essential to create a drainage path, to speed up the healing process and to eradicate the infection. It can be performed as soon as the inflammation dissipates that allows local anesthesia.

Sepsis and more serious complications like cerebral extension found in our series and others $[2,3]$ can occur. Despite of that, ninety two percent of our patients had good outcomes.

\section{Conclusions}

This study has demonstrated that periorbital (preseptal) cellulitis can be diagnosed with clinical signs even if CT-scan states more precision. Instead of that, advanced stage of periorbital cellulitis depending of Chandler stage, will be diagnosed difficully with only cliincal exam. They will require CT-scan. Combined analgesic, antibiotherapy, drainage plus appropriate post-operative cares give good outcomes et restrain aftereffects. This pathology usually evolves favourably but severe complications can occur. Periorbital cellulitis usually have good outcomes if well managed.

\section{References}

[1] Razafindrabe, J. A. B., Randriamanantenasoa, V. H., Andrianasolo, M. F., Rasoarimasy, V. O., Rakotovao, J. D., and Radaviarison, J. B. 2007. "Epidemiological and Clinical Aspect of Dental Cellulitis in Antananarivo." J Med Sci. 7 (7): 1108-11.

[2] Seongmu, L., and Yen, M. T. 2011. "Management of Preseptal and Orbital Cellulitis." Saudi J Ophthal. 25: 21-5.

[3] Ailal, F., Bousfiha, A., Jouhadi, F., Bennani, M., and Abid, A. 2004. "Cellulites orbitaires chez l'enfant à propos d'une étude rétrospective de 33 cas." Med Trop. 64: 359-62.

[4] Donahue, S. P., and Schwartz, G. 1998. "Preseptal and Orbital Cellulitis in Childhood-A Changing Microbiologic Spectrum." AM J Ophthalmol 105: 1902-6.

[5] Uzcategui, N., and Warman, R. 1998. "Clinical Practice Guidelines for the Management of Orbital Cellulitis." $J$ Pediatr Ophthalmol Strabismus 35 (2): 73-9.

[6] Wane, A. M., Ba, E. A., Ndoye-Roth, P. A., Kameni, A., Demedeiros, M. E., Dieng, M., et al. 2005. "Senegalese Experience of Orbital Cellulitis.” J Fr Ophtalmol 28 (10): 1089-94.

[7] Randrianjafisamindrakotroka, O. 2011. Aspects épidémio-cliniques des cellulites préseptales et orbitaires vues dans le service d'ophtalmologie du CHUA-JRA [Thèse]. Antananarivo: Médecine Humaine, 57P. 
[8] Srinnivasa, P. B., and Govardhan, T. 2011. "A Rare Case of Orbital Cellulitis Followed by Therapeutic (Orthodontic) Extraction." J Maxillofac Oral Surg. 10 (3): 257-61.

[9] Devrim, I., Kanra, G., Kara, A., Cengiz, A. B., Orhan, M., Ceyhan, M., et al. 2008. "Preseptal and Orbital Cellulitis: 15-Year Experience with Sulbactam Ampicillin Treatment." Turk J Pediatr. 50 (3): 214-8. (ISSN: 0041-4301).

[10] Diallo, O. R., Balde, N. M., Camara, S. A., and Bah, A. T. 2006. "Les cellulites cervico-faciales chez le patient diabétique au CHU de Conakry." Rev. Col. Odonto-Stomatol. Afr. Chir. Maxillo-fac. 13 (3):13-6.

[11] Beren, B. 2003. "Les anti-inflammatoires non stéroïdiens." Rev Prat. 53: 502-6.

[12] Randriamanantena, T. 2009. Traitement chirurgical des cellulites odontogènes. Antananarivo: Médecine Humaine, $57 \mathrm{p}$.

[13] Jordana, F., Fronty, Y., and Barbrel, P. 2004. "Relations pathologiques oeil-dent: point de vue du stomatologiste et de l'odontologiste." EMC-Dentisterie 1 (4): 417-28.

[14] Pereira, F. P., Velascoe, A. A., Anselmo-Lima, W. T., and Elias Junior, J. 2006. "Computed Tomographic Patterns of Orbital Cellulitis due to Sinusitis." Arq Bras
Oftamol 69 (4): 513-8.

[15] Chemli, H., Mnejja, M., Dhouib, M., Karray, F., Ghorbel, A., and Abdelmoula, M. 2012. "Sinusites Maxillaires D’Origine Dentaire: Traitement Chirurgical." Rev Stomatol Chir Maxillofac 113: 87-90.

[16] El Mansouri, H. 2009. "Cellulite orbitaire: à propos de 24 cas.” J Fr Ophtalmol 32 (1): 1s169.

[17] Laure, B., Tiguemounine, J., Picard, A., and Goga, D. 2004. "Abcès intraorbitaire d'origine dentaire." Rev Stomatol Chir Maxillofac 105 (2): 125-9.

[18] Curtin, H. D. 2006. "Odontogenic Orbital Inflammation: Clinical and CT Findings-Initial Observations." Radiol 239: 187-94.

[19] Wilk, G., Modrzejewska, M., Lachowicz, E., Lisiecka-Opalko, K., Myśliwiec, L., Rutkowski, D., et al. 2012. "From Ophtalmologist to Dentist via Radiology." Pol J Radiol 77 (1): 21-7.

[20] Chang, H. P., Dong, H. J., and Tae, Y. L. 2013. "A Case Report of Odontogenic Orbital Cellulitis Causing Blindness by Severe Tension of Orbit." J Korean Med Sci. 28: 340-3.

[21] Yang, M., Quah, B. L., Seah, L. L., and Looi, A. 2009. "Orbital Cellulitis in Children-Medical Treatment versus Surgical Management.” Orbit 28 (2-3): 124-36. 